\title{
MODELOS DE CALIDAD EN LA GESTIÓN PÚBLICA
}

\author{
JORGE ALBERTO VÁSQUEZ RODRÍGUEZ \\ Escuela de Ciencias de la Administración \\ Universidad Estatal a Distancia, Costa Rica \\ jvasquez@uned.ac.cr
}

\section{RESUMEN}

Los premios de la calidad se encuentran ligados en todo el mundo a los modelos de calidad. El primer premio en el campo de la calidad surgió en Japón en 1951; luego en Colombia en los años setenta, seguidamente en los Estados Unidos en los años ochenta, y en muchos países en todos los continentes, igualmente a partir de los años ochenta. Latinoamérica no fue la excepción. Cada modelo de calidad contiene una serie de criterios y subcriterios que en conjunto se utilizan para evaluar la calidad en una organización. Se trata de identificar áreas de mejora y evidenciar las mejores prácticas en la gestión de la calidad. Con el surgimiento de la Nueva Gestión Pública en los años ochenta; según la cual los conceptos, prácticas, modelos e instrumentos de la gestión privada se trasladan a la gestión pública, surgen una serie de modelos de calidad en esta última, que fueron asociados a premios de la calidad. En Costa Rica, en la segunda administración de Óscar Arias Sánchez (2006-2010), se oficializa un modelo de gestión de calidad para la gestión pública, con su correspondiente premio.

PALABRAS CLAVE: CALIDAD, SERVICIOS PÚBLICOS, GESTIÓN PÚBLICA, MODELOS DE CALIDAD.

\section{ABSTRACT}

Quality awards are linked to worldwide quality models. First prizes in the field of quality emerged in Japan in 1951; then, they appeared in the United States in the 80's, as well as in many other countries in all continents. Latin America was no exception. Each model contains a number of quality criteria and sub- criteria which together are used to evaluate the quality of an organization. They help identify areas for improvement and highlight best practices in quality management. With the emergence of New Public Management policies in the 80 's - where concepts, practices, models and tools move from private management to public administration- a number of quality models associated with quality awards arose. In Costa Rica, in the second administration of Oscar Arias Sánchez (2006-2010), a model of quality management in public administration with its corresponding award was made official.

KEYWORDS: QUALITY, PUBLIC SERVICES, GOVERNANCE, QUALITY MODELS.

\section{INTRODUCCIÓN}

Uno de los elementos fundamentales para el fomento de la calidad son los modelos de calidad, los cuales nacieron asociados a un premio de esta índole. El antecedente de mayor renombre es el denominado "Premio Deming", dedicado al doctor William Edwards Deming (1900-1993), por sus aportes en el fomento de la calidad en Japón y su incidencia en el desarrollo económico del país, después de la Segunda Guerra Mundial (19391945). A él se le asocia con el modelo Deming de la calidad (Evans y Lindsay, 2008).

En 1975 el Gobierno Colombiano, crea el Premio Colombiano a la Calidad, para el sector público y el privado, distinguiendo la calidad y productividad. 
En 1987, el Congreso de los Estados Unidos promulgó la ley 100-107, donde establece el Premio Nacional de Calidad Malcom Baldrige, en honor al secretario del Comercio de la administración Ronald Reagan (1981-1989), Howard Malcolm "Mac" Baldrige, quien impulsó la calidad en ese país. Este premio tiene asociado el modelo Malcom Baldrige de la calidad (Evans y Lindsay, 2008).

En 1991 la Fundación Europea para la Gestión de la Calidad (en inglés, European Foundation for Quality Management, EFQM), estableció el modelo de excelencia EFQM, que es utilizado como criterio de decisión para otorgar el Premio Europeo de la Calidad (Evans y Lindsay, 2008).

En la década de los noventa proliferaron una serie de modelos de calidad alrededor del mundo, la mayoría fundamentados en los modelos Deming, Baldrige y en el europeo. Todos ellos fueron utilizados para otorgar un premio de calidad en sus respectivos países, aunque también surgieron premios otorgados a ciudadanos que se destacaron en esta materia..

Con el desarrollo de la Nueva Gestión Pública, principalmente a partir de los años ochenta y noventa, la cual trasladó algunas técnicas, modelos y conceptos de la esfera privada a la pública; comenzaron a aparecer los modelos de calidad destinados a la gestión pública. Estos modelos también fueron asociados a un premio de la calidad en la gestión pública y, en forma paralela, a los modelos y premios a la calidad que habían sido instituidos en la segunda mitad del siglo XX. Algunas veces se elaboraron versiones específicas para la esfera privada y para la esfera pública, respectivamente (Araya y Cerpa, 2008).

Los modelos de calidad de la gestión pública proliferaron en Europa, los Estados Unidos de América y otras latitudes, y se observa un gran número de ellos en Latinoamérica, especialmente en los años previos y posteriores al cambio de milenio.
En la primera década del presente siglo, los modelos y premios a la calidad en la gestión pública se establecieron en algunos países centroamericanos. En la segunda administración de Arias Sánchez (2006-2010), se oficializó en Costa Rica un modelo de calidad bajo la misma tónica de asociarlo a un premio. Con esto se pretendía fomentar la calidad en la gestión pública (Henderson, 2011).

\section{Los premios a la calidad}

Desde la creación del Premio Deming en 1951 en Japón, surgen una serie de premios que se encuentran asociados a un modelo de calidad. Un modelo de gestión de calidad consiste en una serie de criterios y subcriterios, generalmente cuantificables, que se ponderan para evaluar y calificar la gestión de la calidad en una determinada organización, e identificar áreas de mejora (Evans y Lindsay, 2008).

Las evaluaciones resultantes de la calificación a partir de un modelo de calidad, son utilizadas para el otorgamiento de premios a la calidad. Y las experiencias de las organizaciones ganadoras, son utilizadas por otras instituciones para mejorar su gestión.

Sobre los modelos de calidad, Henderson nos indica que:

... en el desarrollo del concepto y las técnicas de calidad se sentaron bases que han permitido la construcción de modelos de calidad o excelencia que dan líneas guías a las empresas y organizaciones que tengan interés de mejorar ${ }^{1}$ sus procesos, sus gestiones $y$, en general, cada uno de los aspectos que pertenecen a dicha empresa. Los mo-

1. Proceso sistemático de adecuación de la organización a las nuevas y cambiantes necesidades y expectativas de clientes y otras partes interesadas, realizada mediante la identificación de oportunidades de mejora, y la priorización y ejecución de proyectos de mejora. 
delos no dan pasos a seguir [...] lo que proveen son conceptos clave que deben ser revisados y evaluados, y es a través de esa evaluación, que se logran dar los pasos necesarios hacia la mejora de la organización (Henderson, 2011, p. 221).

\section{TABLA 1}

\section{PRINCIPALES MODELOS DE EXCELENCIA EN LA GESTIÓN}

\begin{tabular}{|c|c|c|c|}
\hline \multirow{2}{*}{ Modelo } & \multirow{2}{*}{ País } & \multicolumn{2}{|l|}{ Premio } \\
\hline & & Denominación & Año \\
\hline Deming & Japón & Deming & 1951 \\
\hline Malcolm Baldridge ${ }^{2}$ & USA & Malcolm Baldridge & 1988 \\
\hline $\begin{array}{l}\text { EFQM (Fundación Europea } \\
\text { para la Administración de } \\
\text { la (alidad) }\end{array}$ & Europa & $\begin{array}{l}\text { Europeo de la } \\
\text { Calidad }\end{array}$ & 1991 \\
\hline $\begin{array}{l}\text { Fundación Iberoamericana } \\
\text { para la Gestión de la } \\
\text { Calidad }\end{array}$ & Iberoamérica & $\begin{array}{l}\text { Premio } \\
\text { Iberoamericano de } \\
\text { la Calidad }\end{array}$ & 1999 \\
\hline
\end{tabular}

Fuente: Henderson, 2011

La mayoría de estos modelos, en especial los de mayor renombre (Deming, Baldridge y EFQ), inspiran la creación de otros patrones de gestión de calidad, con sus correspondientes medios, en Europa, África, Australia y Asia (Evans y Lindsay, 2008).

En la tabla 2 se observan varios premios a la calidad, identificando el país y el año de creación. Como puede observarse, todos estos premios tienen en común el fomento a la calidad en las organizaciones y establecer estándares internacionales.

La creación de premios de la gestión de calidad, según puede observarse en la figura número 1, antes de la década de los ochenta, existieron muy pocos premios. Los pioneros fueron Japón, con el denominado "Premio Deming", y Colombia, cuyo premio fue establecido en 1975.

2. Se puede otorgar a organizaciones de otros países
Es a partir de la década de 1980, precisamente cuando los productos japoneses lideraban el mercado mundial por su calidad, cuando proliferan una gran cantidad de premios, como el de Canadá (1982), el de Escocia (1984) y el Malcolm Baldrige en los Estados Unidos (1987) (Evans, y Lindsay, 2008).

Como se puede observar en la figura 1, en Latinoamérica, los premios a la calidad de la gestión "explotan" principalmente en la década de los noventa. Del estudio de estos premios se infiere que, conforme a su naturaleza, tenían como fin el fomento de la calidad en las organizaciones, pero en el ámbito privado principalmente; como en el caso del Premio Macolm Baldrige.

Los premios a la calidad a nivel mundial, son un indicador de la importancia que ha tomado el tema de la calidad en todo el orbe. De igual forma, en Latinoamérica los premios son un indicador de la importancia de la calidad en la región.

\section{Premios a la calidad en la gestión pública}

En el marco de la Nueva Gestión Pública (NGP), que a partir de la década de los ochenta traslada o adapta los conceptos y herramientas del ámbito privado al público, se introducen los premios de la calidad en la gestión pública, con el propósito de mejorarla (Altaba, 2010). Es así como en 1989, en los Estados Unidos de América, el Instituto Federal de la Calidad (IFC), organiza y gestiona el Premio Presidente, que tiene como prioridad impulsar la calidad total en el Gobierno Federal. Este premio es un reflejo del Malcolm Baldrige, en donde se destina "a aquellos organismos federales de Estados Unidos que hayan implantado la gestión de calidad de una manera ejemplar y presentando servicios de alta calidad a sus clientes/contribuyentes. Trata de apoyar actividades que impulsen las iniciativas de'reinventar'el Gobierno" (Muñoz, 1999, p.143). 


\section{TABLA 2}

\section{PREMIOS NACIONALES DE CALIDAD EN VARIOS PAÍSES DEL MUNDO}

\begin{tabular}{|c|c|c|c|}
\hline País & Premio & $\begin{array}{l}\text { Año en } \\
\text { que se } \\
\text { inició }\end{array}$ & Página web \\
\hline Japón & $\begin{array}{l}\text { Premio Deming a la Gestión Total de la Calidad. }{ }^{3} \text { Es otorgado por } \\
\text { la Unión de Científicos e Ingenieros Japoneses (JUSE) }\end{array}$ & $1950^{4}$ & http://www.juse.or.jp/e/index.html \\
\hline Colombia & Premio Colombiano a la Calidad. & 1975 & http://ccalidad.org/pccindex.htm \\
\hline Canadá & $\begin{array}{l}\text { Premio a la Excelencia de Canadá, otorgado por el Instituto } \\
\text { Nacional de Calidad (National Quality Institute). }\end{array}$ & 1982 & http://www.nqi.com/ \\
\hline Escocia & $\begin{array}{l}\text { Premio Escocés a la Excelencia en los Negocios de la Fundación } \\
\text { Escocesa de la Calidad. }\end{array}$ & 1984 & http://www.qualityscotland.co.uk/ \\
\hline Estados Unidos & $\begin{array}{l}\text { Malcolm Baldrige National Quality Award. Es administrado por el } \\
\text { Departamento de Comercio del Gobierno, a través de su Instituto } \\
\text { de Estándares y Tecnología (NIST). }\end{array}$ & 1987 & http://www.nist.gov/baldrige/index.cfm \\
\hline México & Premio Nacional de Calidad & 1990 & http://www.economia-premios.gob.mx/calidad/intranet.asp \\
\hline Brasil & $\begin{array}{l}\text { Premio Nacional da Qualidade, de la Fundación para el Premio } \\
\text { Nacional a la Calidad. }\end{array}$ & 1992 & http://www.fnq.org.br/avalie-se/pnq \\
\hline Europa & $\begin{array}{l}\text { Premio Europeo a la Calidad de la Fundación Europea para la } \\
\text { Gestión de Calidad (EFQM) (tiene su base en Bruselas). }\end{array}$ & 1992 & http://www.efqm.org/ \\
\hline Uruguay & $\begin{array}{l}\text { Premio Nacional a la Calidad, reconocimiento que hace el } \\
\text { Gobierno, con base en el Modelo de Mejora Continua. }\end{array}$ & 1992 & http://www.inacal.org.uy/?q=reconocimientos \\
\hline España & Premio Príncipe Felipe a la Excelencia Empresarial. & 1993 & http://www.mityc.es/principefelipe \\
\hline Argentina & Premio Nacional a la Calidad. & 1994 & http://www.premiocalidad.org.ar/index_2.html \\
\hline Ecuador & Premio Nacional a la Calidad del Ecuador. ${ }^{5}$ & 1994 & http://www.calidadtotal.org/corporacion/index.php \\
\hline Sudáfrica & $\begin{array}{l}\text { Premio Sudafricano a la Excelencia. Este premio se otorga con base } \\
\text { en el Modelo de Excelencia Sudafricano, que combina los modelos } \\
\text { de Europa y Estados Unidos. Es administrado por la Fundación } \\
\text { para la Excelencia Sudafricana. }\end{array}$ & 1997 & http://www.saef.co.za/ \\
\hline Chile & Premio Nacional a la Calidad. & 1997 & http://www.chilecalidad.cl/ \\
\hline Perú & $\begin{array}{l}\text { Premio Nacional a la Calidad. Este galardón está dividido en tres } \\
\text { categorías: empresas de producción de bienes, empresas de } \\
\text { servicios y pequeñas empresas. }\end{array}$ & $1998^{6}$ & http://www.cdi.org.pe/premio_otros.htm \\
\hline Cuba & Premio Nacional de Calidad de la República de Cuba. & 1999 & http://www.nc.cubaindustria.cu/ \\
\hline Paraguay & $\begin{array}{l}\text { Premio Nacional a la Calidad y la Excelencia en Gestión. El premio } \\
\text { es administrado por la Fundación Premio Nacional a la Calidad y } \\
\text { Excelencia. }\end{array}$ & 1999 & http://www.pyglobal.com/calidad4.php \\
\hline Fundibeq & Premio Iberoamericano de la Calidad. & 2000 & http://www.fundibeq.org \\
\hline El Salvador & Premio Nacional a la Calidad de El Salvador & 2001 & http://premiocalidad.presidencia.gob.sv/ \\
\hline $\begin{array}{l}\text { República } \\
\text { Dominicana }\end{array}$ & $\begin{array}{l}\text { Premio Nacional a la Calidad y Reconocimiento a las Prácticas } \\
\text { Promisorias en el Sector Público }\end{array}$ & 2005 & http://map.gob.do/inicio/premio-nacional-a-la-calidad/ \\
\hline
\end{tabular}

Fuente: Elaboración propia.

3. Lleva su nombre en honor al Dr. W. E. Deming.

4. Se oficializa en 1950 y un año después, en 1951, se entrega el primero.

5. La Corporación Ecuatoriana de la Calidad Total es la entidad responsable de la administración de este premio.

6. Anteriormente a esta fecha instalado el premio a la Calidad en 1998, así como el curso Motivación de Mejora, desde 1991. 


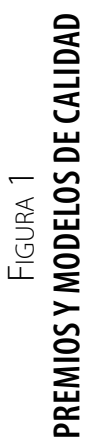
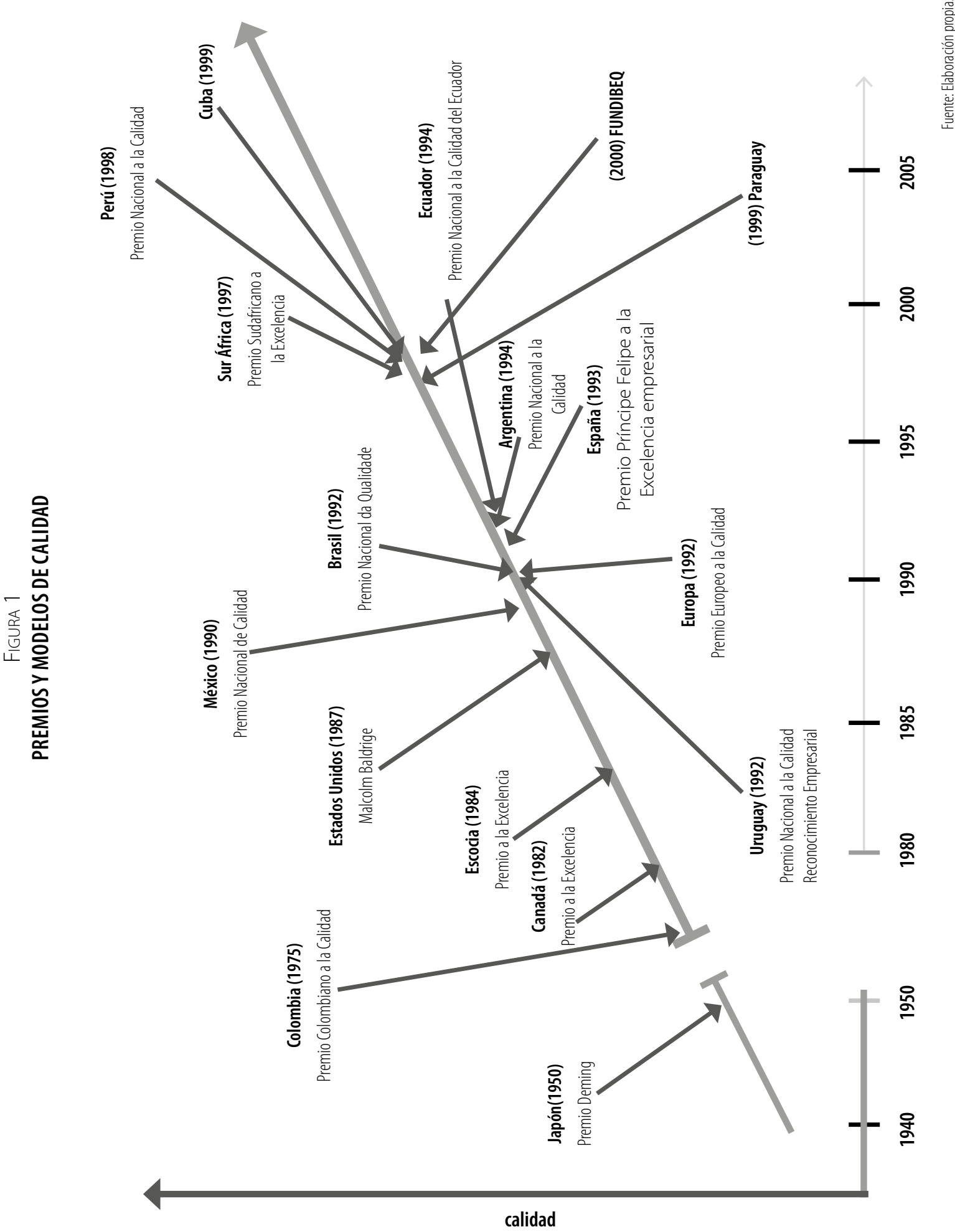
En 1988 se creó el Premio Europeo a la Calidad, otorgado por la Fundación Europea para la Gestión de la Calidad (EFQM). Posteriormente, en 1997, la Fundación adaptó el premio para el sector público y, con ese propósito publicó las directrices para ese sector (Aguilera, 2010).

De conformidad con el EFQM, "la satisfacción de los clientes y empleados y el impacto en la sociedad se consiguen mediante un liderazgo que impulse la política y estrategia, la gestión del personal, los recursos y los procesos hacia la consecución de la excelencia en los resultados empresariales" (Muñoz, 1999, p. 137).

En el 2000, el Grupo de Servicios Públicos Innovadores (IPSG, por sus siglas en inglés) de la Red Europea de la Administración Pública, presentó el Marco Común de Evolución (CAF por su siglas en inglés), que es una "[...] herramienta de gestión de calidad adaptada específicamente para las características del sector público [...] basados en los principios de la gestión de calidad total, TQM y derivado de los modelos" (MAP, 2006). Esta herramienta tiene como base el modelo EFQM.

La Fundación Iberoamericana para la Gestión de la Calidad impulsó, en 1999, el Modelo Iberoamericano de Excelencia en la Gestión. A partir de ese año fue la base para otorgar el Premio Iberoamericano de Excelencia en la Gestión. En la década siguiente, la Fundación crea la versión del modelo para la Administración Pública.

En el marco de la NGP, en los países de Europa fructifican una serie de premios a la calidad en el sector público. Este mismo fenómeno se presentó también en Latinoamérica.

\section{El componente de la calidad de la Nue- va Gestión Pública en América Latina}

En Latinoamérica, al igual que en el resto del mundo, como se observa en la figura 1, anterior, el tema de la calidad se retoma muy fuertemente y se es- tablecen una serie de premios de calidad. Estos premios brindan un reconocimiento a las organizaciones que se han destacado en esa área y las mismas se constituyen en experiencias dignas de considerar por el resto de las organizaciones.

El Centro Latinoamericano de Administración del Desarrollo $(C L A D)^{7}$ fundamentado en la experiencia en Latinoamérica e Iberoamérica, establece la Carta Iberoamericana de la Calidad en la Gestión Pública (en adelante CICGP), la cual vincula la calidad en la gestión pública con dos propósitos fundamentales de un buen gobierno democrático (CLAD, 2008):

- $\quad$ "Debe estar referenciada a la satisfacción del ciudadano, ya sea como usuario o beneficiario de servicios y programas públicos o como legítimo participante en el proceso, formulación, ejecución y control de las políticas públicas, bajo el principio de corresponsabilidad social." (CLAD,2008, p.4)

- "Tiene que orientarse a resultados, por lo que debe estar sujeto a diversos controles sobre sus acciones; esto supone, entre otras modalidades, la responsabilización del ejercicio de la autoridad pública, por medio del control social y la rendición periódica de cuentas." (CLAD, 2008, p.4)

Hay una serie de premios a la calidad en Latinoamérica a los que pueden optar las organizaciones públicas, como puede observarse en la Tabla 3.

7. Los compromisos adquiridos por el país en el marco del CLAD, fueron implementados en la administración Chichilla Miranda (2000-2006), por medio del Premio Nacional a la Calidad en la Gestión Pública, al reconocimiento de prácticas promisorias y a las cartas con el ciudadano, más adelante nos referimos en detalle a cada uno de ellos. La Carta Iberoamericana de la Calidad del CLAD está siendo utilizada por el Instituto Centroamericana de Administración Pública (ICAP). 
TABLA 3

\section{LATINOAMÉRICA: PREMIOS DE CALIDAD EN QUE SE PARTICIPA A LAS ORGANIZACIONES PÚBLICAS ${ }^{45}$}

\begin{tabular}{|l|l|l|l|}
\hline \multicolumn{1}{|c|}{ Año } & \multicolumn{1}{|c|}{ País } & \multicolumn{1}{|c|}{ Denominación del Premio } & Ámbito \\
\hline 1975 & Colombia & Premio Colombiano a la Calidad & Público y privado \\
\hline 1990 & México & Premio Nacional de Calidad & Público y privado \\
\hline 1991 & Brasil & Premio Nacional de la Calidad & Público y privado \\
\hline $1991^{8}$ & Perú & Premio Nacional a la Calidad & Público y privado \\
\hline $1993^{9}$ & Argentina & Premio Nacional a la Calidad & $\begin{array}{l}\text { Privado con posibilidad de participación } \\
\text { de instituciones públicas }\end{array}$ \\
\hline 1993 & Uruguay & Premio Nacional a la Calidad & Público y privado \\
\hline 1996 & Chile & Premio Nacional a la Calidad y Gestión de Excelencia & Público y privado \\
\hline 1999 & Cuba & Premio Nacional de Calidad & Público y privado \\
\hline 1999 & Paraguay & Premio Nacional a la Calidad y Gestión de Excelencia & Público y privado \\
\hline 2000 & Iberoamérica & Premio lberoamericano a la Calidad & Público y privado \\
\hline 2001 & Ecuador & Premio Nacional de Calidad & Público y privado \\
\hline 2005 & República Dominicana & Premio Nacional a la Calidad y el Reconocimiento a las & Público \\
\hline 2010 & Costa Rica & $\begin{array}{l}\text { Premio Nacional a la Calidad y el Reconocimiento a las } \\
\text { Prácticas Promisorias en el Sector Público }\end{array}$ & Público \\
\hline
\end{tabular}

Fuente: Elaboración propia.

Según Henderson (2011), en las administraciones públicas de Centroamérica y República Dominica, se han empezado a adoptar modelos de gestión de la calidad, que se han concretado en premios nacionales a la calidad en la gestión pública. Todo esto dentro del marco de la Nueva Gestión Pública y con el insumo que ofrece la Carta Iberoamericana de Calidad en la Gestión Pública.

En esta región se han constituido tres premios a la calidad en la gestión pública, como se puede observar en la tabla 4.

\section{TABLA 4}

\section{CENTROAMÉRICA: PREMIOS A LA CALIDAD EN EL ÁMBITO PÚBLICO}

\begin{tabular}{|l|l|l|}
\hline \multicolumn{3}{|c|}{ Centroamérica - Premios de calidad exclusivos para el sector público } \\
\hline 2005 & República Dominicana ${ }^{10}$ & Premio Nacional a la Calidad y el Reconocimiento a las Prácticas Promisorias en el Sector Público \\
\hline 2010 & Costa Rica & Premio Nacional a la Calidad y Reconocimiento a Prácticas Promisorias en la Gestión Pública \\
\hline 2011 & Guatemala & Premio Nacional a la Calidad y Reconocimiento a las Mejores Prácticas en la Administración Pública \\
\hline
\end{tabular}

Fuente: Investigación propia a partir de datos obtenidos en el ICAP.

8. El premio sufre varias transformaciones desde 1991, constituyéndose en el Premio Nacional de la Calidad, en el año 2002.

9. En el 2010 se instala uno especialmente para el sector público.

10. Este premio es anterior a la Carta Iberoamericana de la Calidad de la Gestión Pública del 2008. 
Los premios a la calidad en la gestión pública a nivel latinoamericano, incluyendo Centroamérica, son un indicador de la importancia que ha tomado el tema de la calidad en la Administración Pública.

\section{Modelos de la calidad en la gestión pública}

Aunque en varios países, sobre todo en los de Europa, se han desarrollado varios modelos para la calidad de los servicios públicos (Aguilera, 2010), nos referiremos únicamente a los siguientes:

- $\quad$ EFQM de Excelencia de la Fundación Europea para la Gestión de la Calidad.

- El Marco Común de Evaluación (CAF).

- $\quad$ El Modelo de Evaluación, Aprendizaje y Mejora (EVAM).

- $\quad$ El Modelo Iberoamericano en la Gestión Pública, modalidad administración pública.

- Carta Iberoamericana de la Calidad.

\section{El modelo EFQM de excelencia para la Administración Pública, de la Fundación Europea para la Gestión de la Calidad}

Desde 1999, el Ministerio de Administraciones Públicas de España ha promovido la aplicación de un modelo de referencia continental, como es el Modelo EFQM de Excelencia, para poner en marcha el programa de autoevaluación de las organizaciones. Ese mismo año se desarrolló la Guía de Autoevaluación para la Administración Pública, con el fin de poner a disposición de los gestores públicos, un instrumento práctico que les ayudara a realizar la autoevaluación de sus organizaciones, a partir de las directrices del Modelo EFQM de Excelencia. A la fecha se han publicado cuatro ediciones de esta guía (MAP, 2006).

El Modelo EFQM tiene una versión para el sector público y las organizaciones de voluntariado, que es a la que hacemos referencia.
De conformidad con el Ministerio de Administraciones Públicas (MAP) de España (MAP, 2006), el Modelo EFQM de Excelencia tiene un carácter globalizador que cubre todos los aspectos del funcionamiento de una organización. Esto permite efectuar una aproximación integral a todos sus procesos de desarrollo y a todos los niveles de la estructura, dentro de un marco de referencia que se basa en los conceptos fundamentales de la excelencia. De esta forma, el análisis y la transformación de las organizaciones se apoyan en un conjunto de principios que dota de significado a las acciones, tanto individuales como colectivas, que se desarrollan en el seno de la organización.

Entonces, de acuerdo con el MAP (2006), el Modelo EFQM de Excelencia es un marco de trabajo no prescriptivo, que reconoce que la excelencia de una organización se puede lograr de manera sostenida mediante distintos enfoques. Los conceptos fundamentales de la excelencia resultan aplicables a organizaciones de todo tipo, independientemente de su sector o tamaño, y constituyen la base del Modelo EFQM de Excelencia.

A partir de lo expuesto en las guías para la aplicación del modelo EFQM en la Administración, editadas por el Ministerio de Administraciones Públicas de España, este modelo reconoce que la excelencia en todo lo referente a resultados y rendimiento de una organización se puede lograr de manera sostenida mediante distintos enfoques. El modelo se fundamenta en lo siguiente:

Los resultados excelentes con respecto al Rendimiento general de la Organización, a los Clientes, las Personas y la Sociedad en la que actúa, se logran mediante un Liderazgo que dirija e impulse la Política y Estrategia, que se hará realidad a través de las Personas de la Organización, las Alianzas y Recursos y los Procesos (MAP, 2006, p. 8).

El modelo puede visualizarse en la figura 2.

Para evaluar cada subcriterio, la MAP ha desarrollado una serie de guías de evaluación para la Administración Pública, la que de conformidad con los principios de calidad, se mejora continuamente. 


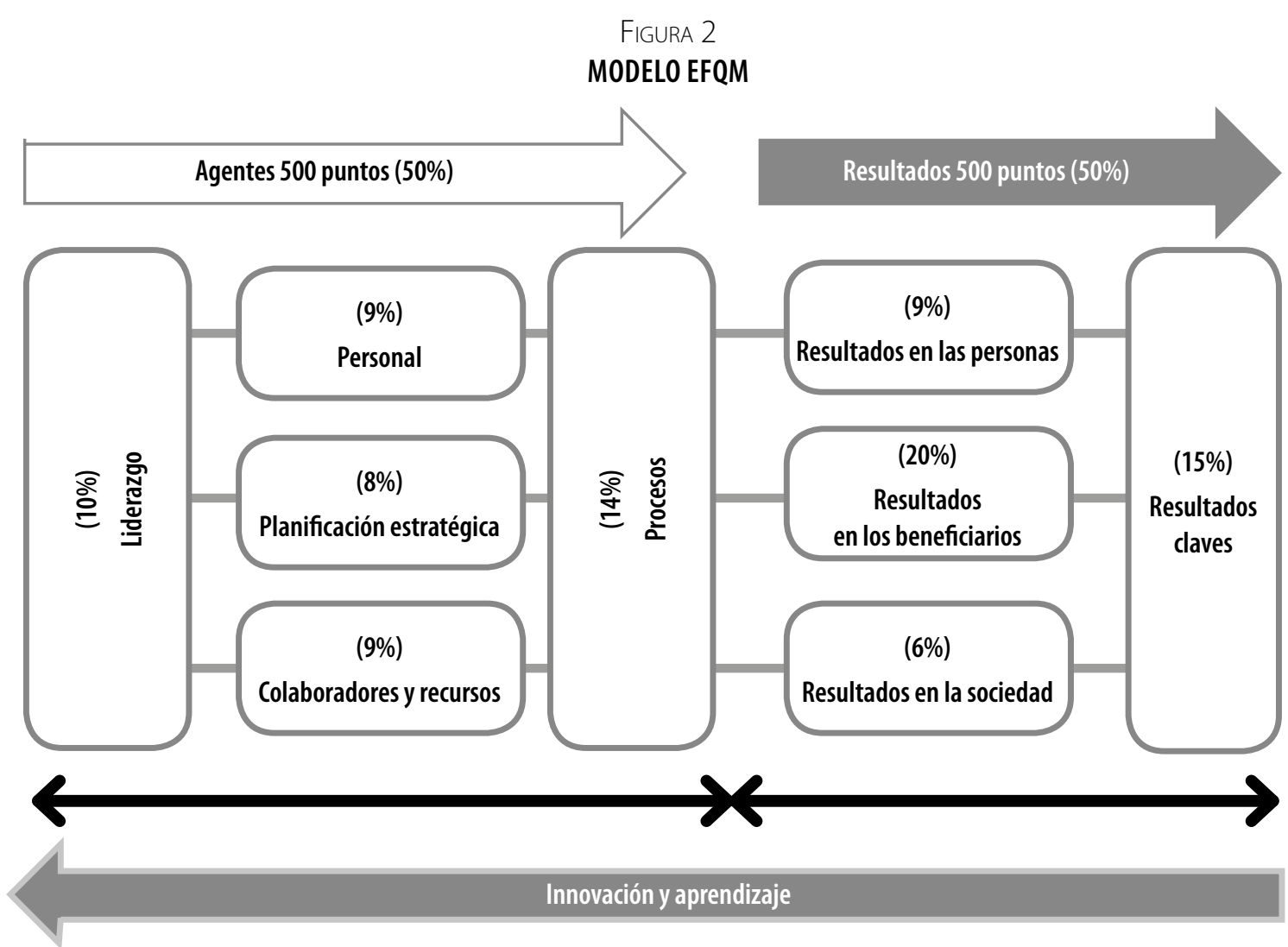

Fuente: Fundación Europea para la Gestión de la Calidad y Ministerio de Administraciones Públicas de España.

La sumatoria de los criterios nos brinda una calificación global de la gestión pública de la organización; además, en cada uno de esos criterios se puede determinar oportunidades de mejora.

\section{El Marco Común de Evaluación (CAF) ${ }^{11}$}

El Marco Común de Evaluación (CAF) es:

[...] una herramienta de gestión de la calidad total inspirada en el Modelo de Excelencia de la Fundación Europea para la Gestión

11. Información tomada de los textos del Ministerio de Administraciones Públicas de España, con modificaciones de nuestra parte para facilitar la argumentación. No obstante, la línea argumentativa, así como la interpretación de los textos y otros aspectos de forma, son de nuestra responsabilidad. de la Calidad (EFQM) y en el Modelo de la Universidad Alemana de Ciencias Administrativas de Speyer. Está basado en la premisa de que los resultados excelentes en el rendimiento de la organización, en los ciudadanos/clientes, en las personas y en la sociedad, se alcanzan por medio de un liderazgo que dirija la estrategia y la planificación, las personas, las alianzas y los recursos y procesos. El modelo examina la organización desde distintos ángulos a la vez, con un enfoque holístico del análisis del rendimiento de la organización (MAP, 2007, p.8).

Este modelo fue desarrollado por el Grupo de Servicios Públicos Innovadores (IPSG), del Ministerio de Administraciones Públicas de España. 
El Marco Común de Evaluación (CAF), tiene como propósitos principales:

1. Introducir a la Administración Pública de forma progresiva en los principios de gestión de la calidad total, y guiarla por medio del conocimiento y el uso de la autoevaluación. Esto a partir de la planificación y el desarrollo de actividades, hasta completar el ciclo "planificar, desarrollar, controlar y actuar" (PDCA).

2. Facilitar la autoevaluación de una organización pública con el fin de obtener un diagnóstico y definir acciones de mejora.

3. Hacer de puente entre los diferentes modelos que se usan en la gestión de la calidad.
4. Facilitar el benchlearning entre las organizaciones del sector público.

El modelo CAF puede visualizarse en la figura 3, el que fue elaborado por el Grupo de Servicios Públicos Innovadores (IPSG) del Ministerio de Administraciones Públicas de España. Si lo comparamos con el Modelo de Excelencia de la Fundación Europea para la Gestión de la Calidad (EFQM), encontramos una similitud entre los criterios; no obstante, los subcriterios en muchos casos son distintos.

Al igual que todos los modelos de calidad, la estructura de criterios identifica los principales aspectos que deben ser considerados en el análisis de cualquier organización pública.

FIGURA 3

MODELO CAF

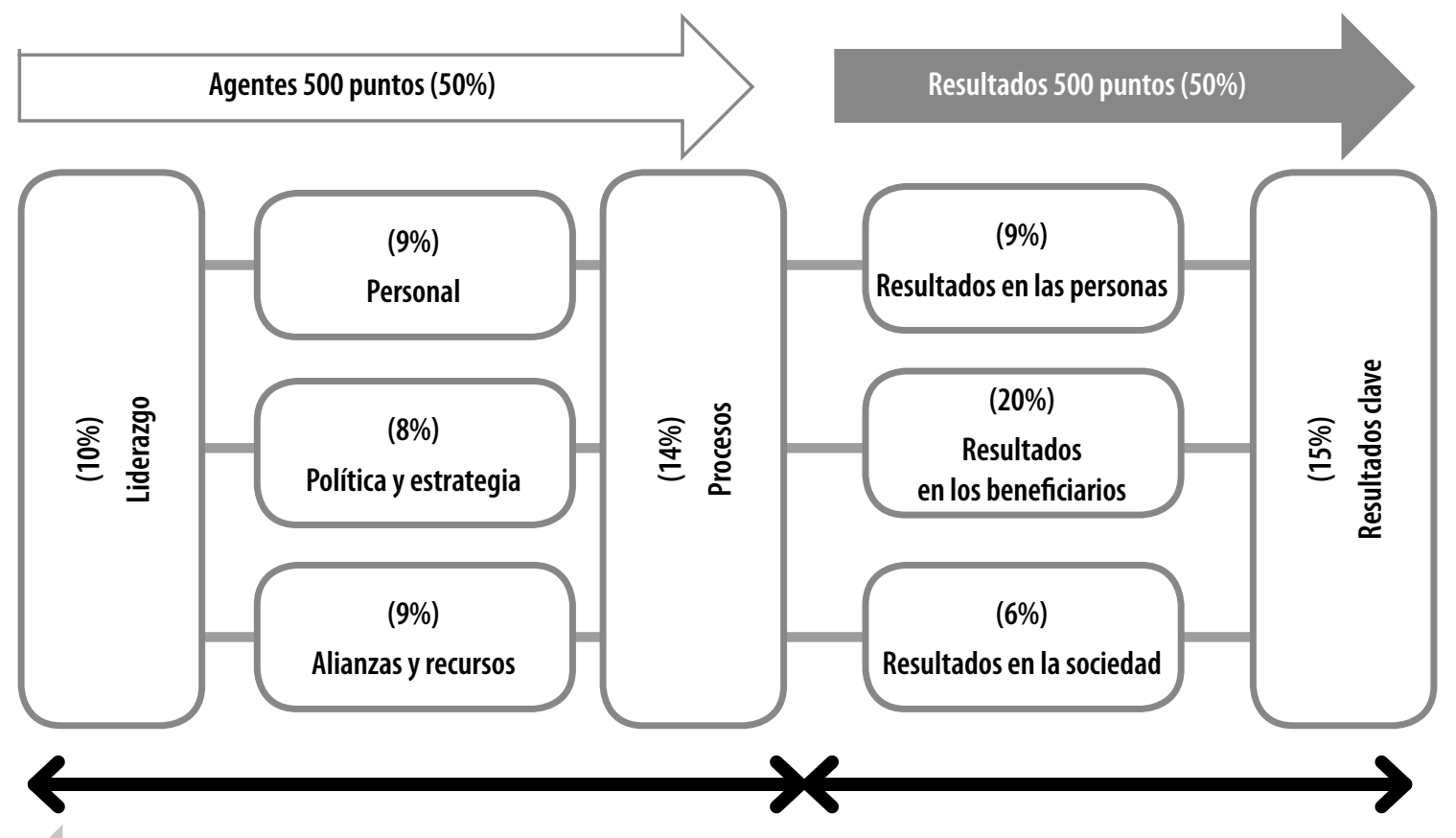

Fuente: Ministerio de Administraciones Públicas, España. 
- Los criterios 1 a 5 se refieren a los agentes facilitadores de una organización y determinan lo que hace y cómo enfoca sus tareas para alcanzar los resultados deseados.

- En los criterios 6 a 9, los resultados alcanzados en las áreas de los ciudadanos/clientes, las personas, la sociedad y los resultados clave del rendimiento se miden por medio de medidas de percepción y se evalúan con indicadores internos. Cada criterio se descompone en una serie de subcriterios.

En la figura 3 se puede observar la división de criterios y subcriterios del modelo CAF.

El CAF proporciona (MAP, 2006) lo siguiente:

- Una evaluación basada en evidencias frente a un conjunto de criterios. que han sido ampliamente aceptados en el sector público de Europa.

- Oportunidades para identificar el progreso y destacar los logros alcanzados.

- Un medio para dar coherencia a la dirección y consenso sobre aquello que es preciso hacer para mejorar una organización.

- Un nexo de unión entre los resultados a alcanzar y las prácticas que los apoyan o agentes facilitadores.

- Un medio para generar entusiasmo entre los empleados de la organización, involucrándolos en los procesos de mejora.

- Oportunidades para promover y compartir buenas prácticas entre diferentes áreas de una organización y entre distintas organizaciones.
- Un medio para integrar iniciativas de calidad en la actividad normal de la organización.

- Un medio para medir el progreso en el tiempo, realizando autoevaluaciones periódicas.

La suma de los criterios brinda una calificación global de la gestión pública de la organización; además, en cada uno de esos criterios se pueden determinar oportunidades de mejora.

\section{El Modelo de Evaluación, Aprendizaje y Mejora (EVAM)}

El desarrollo del Modelo EVAM tiene los siguientes objetivos:

- Realizar la evaluación externa de las organizaciones que no han iniciado su autoevaluación.

- Promover el proceso de evaluación en las organizaciones de la administración general del Estado.

- Facilitar su incorporación gradual al proceso de evaluación.

- Poner a su disposición un instrumento inicial de evaluación para favorecer los primeros pasos en la mejora y el camino a la excelencia.

- Suministrar a estas organizaciones las metodologías y acciones a seguir, que permitan el avance en la mejora de la gestión.

Como se puede observar en la Figura 4, los ejes del modelo EVAM son: i) política, planificación y estrategia a través del liderazgo; ii) procesos; iii) personas; iv) alianzas y recursos; y v) resultados. 
FIGURA 4

MODELO EVAM

\section{EJE TRANSVERSAL: Comunicación}

Fuente: Aeval, 2009

De conformidad con el MAP (MAP, 2006), la lógica subyacente en este sistema de evaluación es la del ciclo PDCA (planificar, desarrollar, controlar, actuar); de tal forma que el orden de presentación de los ejes y aspectos de evaluación es el que sigue:

- Definición de la política y estrategia de la organización basada en políticas públicas, conforme con los requisitos de los usuarios o ciudadanos y de la comunicación externa e interna de la misma.

- Despliegue de la política y estrategia a través de planes operativos que expliciten los objetivos organizativos.
- Planificación y despliegue de los procesos de acuerdo con la política y la estrategia.

- Gestión de recursos adecuada a la política y estrategia organizativa: recursos humanos, recursos materiales o alianzas.

- Determinación de mecanismos de seguimiento del grado de cumplimiento de la política y estrategia organizativa.

- Planificación y desarrollo de la mejora en función de los resultados, para garantizar la consecución de la política y estrategia organizativas (MAP, 2006) 
De acuerdo con el MAP (2006), el diseño del cuestionario de evaluación está basado en la lógica del ciclo PDCA; de forma tal que, para cada una de las cuestiones que desarrollan los aspectos de evaluación del modelo EVAM, se proponen unas preguntas (¿qué?, ¿por qué?, ¿cómo?, ¿dónde?, etc.) que sirven de orientación sobre el tipo de evidencias a examinar. Finalmente, y a efecto de asignar una puntuación a cada una de las cuestiones, como resultado del análisis de las evidencias aportadas, se incluye una escala de 0 a 100, dividida en tramos de diez puntos, al final de cada cuestión.
La suma de los criterios nos brinda una calificación global de la gestión pública de la organización; además de que se puede determinar, en cada uno de esos criterios, oportunidades de mejora.

\section{El Modelo Iberoamericano en la Gestión Pública para Administraciones Públicas}

El Modelo Iberoamericana de Excelencia en la Gestión es creado en 1999 por la Fundación Iberoamericana para la Gestión de la Calidad (FUNDIBEQ). Posteriormente, la FUNDIBEQ establece un modelo específico para la gestión pública, a partir de su modelo de 1999.

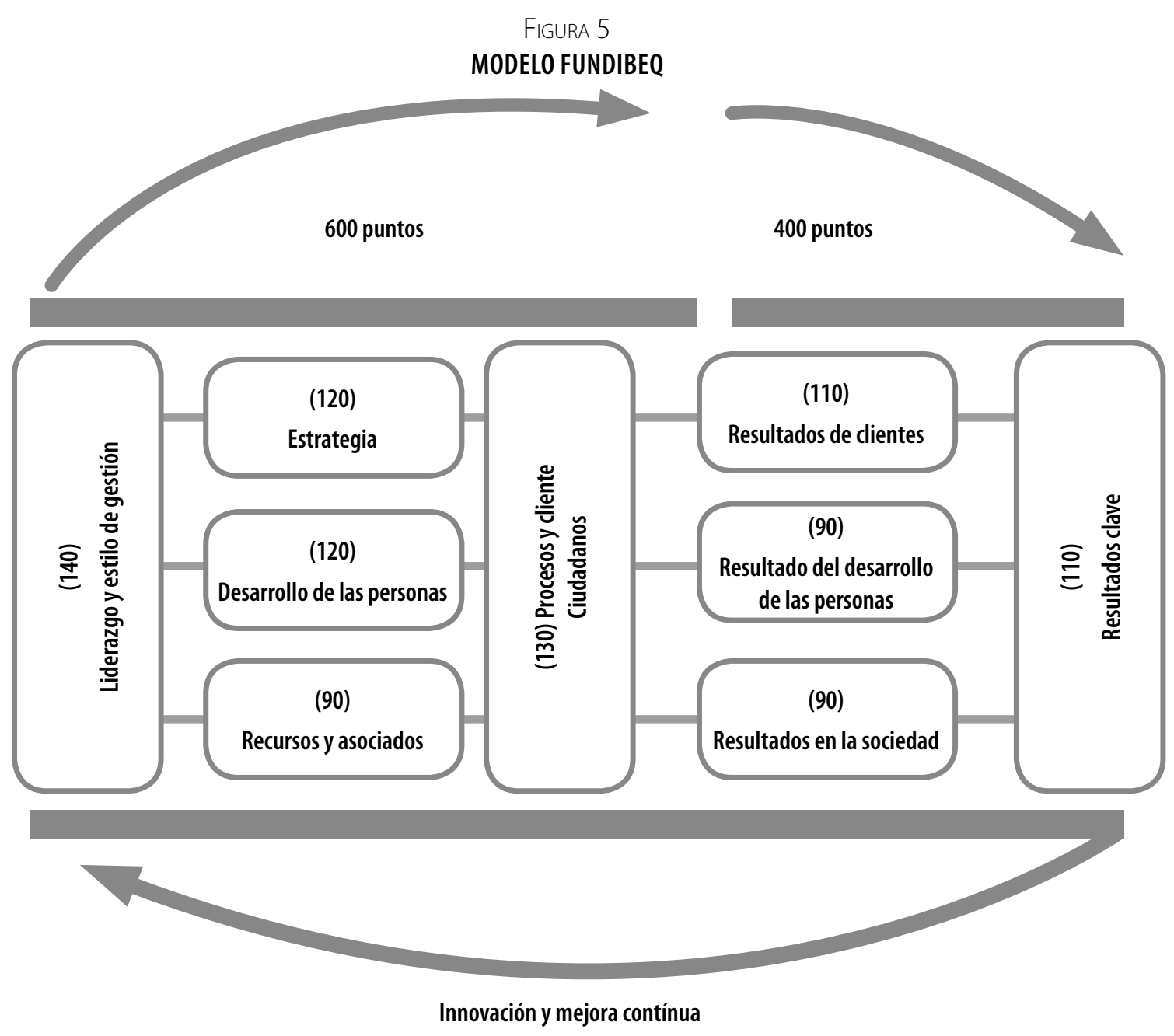

Fuente: Fundación Iberoamericana para la Gestión de la Calidad (FUNDIBEQ) 
Como se puede observar en la figura 5, el modelo se fundamenta en cinco procesos facilitadores y cuatro criterios resultantes. Los cinco procesos facilitadores son: 1.- liderazgo y estilo de gestión; 2.- estrategia; 3.- desarrollo de las personas; 4.- recursos y asociados; $y$, 5.- procesos y clientes o ciudadanos. Cada uno de los procesos facilitadores está dividido para su análisis en cuatro subcriterios y existen cuatro criterios de resultados: 6.- resultados de clientes o ciudadanos; 7.- resultados del desarrollo de las personas; 8.- resultados de la sociedad; y, 9.- resultados globales. Cada uno de estos últimos criterios, tiene dos subcriterios.

\section{El Modelo de la Carta Iberoamericana de la Calidad en la Gestión Pública}

El tema de calidad en los servicios públicos se ha introducido recientemente en todos los países latinoamericanos y ha sido retomado por el Centro Latinoamericano de Administración para el Desarrollo (CLAD).

El CLAD es un organismo público internacional, de carácter intergubernamental, que se constituyó en el año 1972, bajo la iniciativa de los gobiernos de México, Perú y Venezuela. Su creación fue recomendada por la Asamblea General de las Naciones Unidas (resolución 2802 - XXVI), con la idea de establecer una entidad regional que tuviera como eje de su actividad la modernización de las administraciones públicas, un factor estratégico en el proceso de desarrollo económico y social.

Su misión es promover el análisis y el intercambio de experiencias y conocimientos en torno a la reforma del Estado y la modernización de la Administración Pública. Esto mediante la organización de reuniones internacionales especializadas, la publicación de obras, la prestación de servicios de documentación e información, la realización de estudios e investigaciones y la ejecución de actividades de cooperación técni- ca entre sus países miembros y provenientes de otras regiones.

De acuerdo con dicha misión, el CLAD realizó las gestiones para que la Carta Iberoamericana de la Calidad en la Gestión Pública, fuera aprobada por la X Conferencia Iberoamericana de Ministros de Administración Pública y Reforma del Estado, que se celebró en San Salvador (El Salvador) los días 26 y 27 de junio de 2008.

Según la Carta Iberoamericana de la Calidad en la Gestión Pública, los servicios públicos deben cumplir con los siguientes principios de calidad:

- $\quad$ Principio n. ${ }^{\circ}$ 1. Servicio público.

- Principio n. 2. Legitimidad democrática.

- Principio n. ⒊ Transparencia y participación ciudadana.

- Principio n. ${ }^{\circ} 4$. Legalidad.

- Principio n. ․ 5. Coordinación y cooperación.

- Principio n. ㅇ. Ética pública.

- Principio n. 07 . Acceso universal.

- Principio n. ․ 8. Continuidad en la prestación de servicios.

- $\quad$ Principio n. ․ 9. Imparcialidad.

- Principio n. ${ }^{\circ}$ 10. Eficacia.

- Principio n. ${ }^{\circ} 11$. Eficiencia.

- Principio n. ${ }^{0}$ 12. Economía.

- Principio n. 0 13. Responsabilidad.

- Principio n. o 14. Evaluación permanente y mejora continua.

Solo luego de la combinación de esos principios, tenemos calidad en los servicios públicos, ya que con ellos tendríamos servicios que se extienden a toda la ciudadanía, dentro de un marco de legitimidad democrática, transparencia y legalidad. Se pretende con esto que en el balance de la calidad de los servicios públicos, imperen la eficiencia, la eficacia y la mejora continua. 


\section{Premio Nacional a la Calidad en la Gestión Pública}

Tomando en cuenta la experiencia de los premios nacionales otorgados en varios países, así como la del Premio Iberoamericano de Calidad, el Ministerio de Planificación Nacional y Política Económica (MIDEPLAN) gestionó ante el CLAD una solicitud de apoyo técnico para el 2009. Esto con el propósito de crear un premio nacional que promueva la innovación y el mejoramiento de la gestión integral. El establecimiento de un Premio a la Calidad en la Gestión Pública propiciaría el reconocimiento de instituciones públicas destacadas por contar con sistemas de gestión avanzados; además del intercambio y aprendizaje de experiencias exitosas y el uso de los criterios del modelo del premio, como una guía fundamental en el desarrollo de la gestión hacia la calidad, la productividad y la mejora en la prestación de los servicios públicos (Calderón y Castellón, 2011, p.366).

El CLAD envió al país al doctor Luis Tenorio Puente, quien asesoró a los funcionarios de MIDEPLANy de la Dirección General de Servicio Civil respecto de la instauración del premio, antes de la oficialización del mismo mediante el decreto n³5925-MP-PLAN.

Adicionalmente se contó con el apoyo de la Agencia Española de Cooperación Internacional para el Desarrollo (AECID), la Facultad Latinoamericana de Ciencias Sociales (FLACSO), el Sistema para la Integración Centroamericana (SICA), la Fundación Iberoamericana para la Gestión de la Calidad (Fundibeq) y el Instituto Centroamericano de Administración Pública (ICAP) (ECA, 2012, p.3).

En la segunda administración Arias Sánchez (1994-1998), el 8 de abril de 2010, se oficializa el Premio Nacional a la Calidad en la Gestión Pública y el reconocimiento a prácticas promisorias en la gestión pública, mediante la publicación del decreto ejecutivo n. ${ }^{\circ}$ 35925-MP-PLAN.
Con esto, Costa Rica se convierte en el primer país centroamericano en instaurar un premio nacional a la calidad en la gestión pública, lo que ya había hecho República Dominicana en el año 2005. Posteriormente (en el año 2011), se oficializa un premio similar en Guatemala.

De acuerdo con Calderón y Castellón (2011, p. 365-366), con la instauración del premio, el Gobierno de la República busca alcanzar los siguientes objetivos específicos:

- Fortalecer la gestión pública costarricense mediante el establecimiento del Premio a la Calidad en la Gestión Pública. Esto permitirá el intercambio de experiencias exitosas para una mejora sustancial en la entrega de los servicios públicos costarricenses.

- Fortalecer la capacidad de gestión estatal en la prestación de los servicios públicos, mediante la formación de funcionarios públicos en la aplicación de métodos y técnicas modernas que permitan la implementación de un modelo de excelencia en la calidad en la gestión pública costarricense (Calderón y Castellón, 2011, p. 365).

- $\quad$ Promover el desarrollo y la difusión de procesos, acciones, esfuerzos, prácticas y sistemas destinados al mejoramiento continuo de la calidad en la prestación de los servicios públicos que se originan en el sector público costarricense, con el propósito de satisfacer las necesidades y expectativas de sus usuarios y beneficiarios, con la finalidad de apoyar la modernización y competitividad de las instituciones que la conforman, apoyándose en el Sistema Nacional de Contralorías de Servicios (Calderón y Castellón, 2011, pp. 365-366).

Las bases del premio nacional se fundamentan en siete criterios y subcriterios de puntuación los cuales se califican para el otorgamiento del premio (ver tabla 4). 
TABLA 4

\section{COSTA RICA: CRITERIOS Y SUBCRITERIOS PARA LA CALIFICACIÓN DEL PREMIO NACIONAL A LA CALIDAD EN LA GESTIÓN PÚBLICA}

\begin{tabular}{|c|c|c|c|}
\hline Criterio & Definición ${ }^{12}$ & Subcriterio & Definición ${ }^{13}$ \\
\hline & $\begin{array}{l}\text { El liderazgo aborda la manera en que } \\
\text { la alta dirección guía y sostiene a la } \\
\text { organización, estableciendo la misión, } \\
\text { la visión, los valores y las expectativas } \\
\text { de desempeño. La atención se dirige a }\end{array}$ & Liderazgo organizacional & $\begin{array}{l}\text { Este subcriterio analiza los aspectos clave de las responsabilidades } \\
\text { de la alta dirección. Examina cómo la alta dirección establece y } \\
\text { comunica la visión y los valores de la organización. Se enfoca en las } \\
\text { acciones de la alta dirección para crear una organización sustenta- } \\
\text { ble, centrada en la ciudadanía (MIDEPLAN, 2008). }\end{array}$ \\
\hline Liderazgo & $\begin{array}{l}\text { su talento humano, mejora su liderazgo } \\
\text { personal, participa en el aprendizaje } \\
\text { organizacional y desarrolla futuros líderes, } \\
\text { mide el desempeño de la organización y } \\
\text { crea un ambiente que propicia un com- } \\
\text { portamiento ético y un alto desempeño. } \\
\text { (MIDEPLAN, 2008). }\end{array}$ & $\begin{array}{l}\text { Gobierno y } \\
\text { responsabilidad social }\end{array}$ & $\begin{array}{l}\text { Este subcriterio analiza los aspectos clave de la organización. Exa- } \\
\text { mina cómo cumple con sus responsabilidades sociales, cómo la alta } \\
\text { dirección asegura que la organización se desempeña legalmente y } \\
\text { en forma ética y cómo la alta dirección y el talento humano incen- } \\
\text { tivan buenas prácticas ciudadanas y se proyectan a la comunidad } \\
\text { (MIDEPLAN, 2008). }\end{array}$ \\
\hline \multirow{2}{*}{$\begin{array}{l}\text { Planificación } \\
\text { estratégica }\end{array}$} & \multirow{2}{*}{$\begin{array}{l}\text { El criterio planificación estratégica exa- } \\
\text { mina cómo la organización desarrolla } \\
\text { sus objetivos estratégicos y los planes } \\
\text { de acción. También examina cómo son } \\
\text { desplegados y modificados si las circuns- } \\
\text { tancias lo requieren y cómo se mide el } \\
\text { avance de los mismos. }\end{array}$} & Desarrollo de estrategias & $\begin{array}{l}\text { Este subcriterio aborda la estrategia organizacional general de la } \\
\text { organización, que puede incluir cambios en la oferta de servicios y } \\
\text { los procesos para el compromiso hacia la ciudadanía. El subcriterio } \\
\text { no incluye el diseño de servicios o las estrategias para conseguir el } \\
\text { compromiso con la ciudadanía (MIDEPLAN, 2008). }\end{array}$ \\
\hline & & Despliegue de estrategias & $\begin{array}{l}\text { Describe cómo la organización transforma sus objetivos estratégi- } \\
\text { cos en planes de acción. Resume los planes de acción y los indi- } \\
\text { cadores clave y mediciones de desempeño relacionados. Proyecta } \\
\text { el desempeño futuro de la organización en dichas mediciones o } \\
\text { indicadores clave (MIDEPLAN, 2008). }\end{array}$ \\
\hline
\end{tabular}

12. Las definiciones son copia exacta de las incluidas por MIDEPLAN en las bases Premio Nacional a la Calidad 2012.

13. Las definiciones son copia exacta de las incluidas por MIDEPLAN en las bases Premio Nacional a la Calidad 2012. 


\begin{tabular}{|c|c|c|c|}
\hline \multirow{2}{*}{$\begin{array}{l}\text { Orientación } \\
\text { hacia la } \\
\text { ciudadanía }\end{array}$} & \multirow{2}{*}{$\begin{array}{l}\text { El criterio orientación hacia la ciudadanía } \\
\text { examina cómo la organización satisface } \\
\text { las necesidades de la ciudadanía. Esta } \\
\text { estrategia de satisfacción incluye cómo } \\
\text { la organización construye una cultura } \\
\text { orientada hacia la ciudadanía. El criterio } \\
\text { enfatiza este compromiso como un } \\
\text { resultado importante de una estrategia } \\
\text { de excelencia en el desempeño, un } \\
\text { aprendizaje, una escucha y una cultura } \\
\text { totalmente orientada a la ciudadanía } \\
\text { (MIDEPLAN, 2008). }\end{array}$} & $\begin{array}{l}\text { Compromiso hacia la } \\
\text { ciudadanía }\end{array}$ & $\begin{array}{l}\text { Compromiso hacia la ciudadanía se refiere a las inversiones de } \\
\text { la organización hacia la ciudadanía en la oferta de servicios. Las } \\
\text { características del compromiso incluyen la retención y la lealtad, } \\
\text { el deseo de la ciudadanía para realizar esfuerzos que incrementen } \\
\text { sus actividades con la organización y los deseos para apoyar } \\
\text { activamente y recomendar la oferta de servicios. Este subcriterio, } \\
\text { examina los procesos de la organización en la construcción de una } \\
\text { cultura orientada hacia la ciudadanía; también examina los meca- } \\
\text { nismos para identificar e innovar la oferta de servicios y apoyar a la } \\
\text { ciudadanía (MIDEPLAN, 2008). }\end{array}$ \\
\hline & & Voz de la ciudadanía & $\begin{array}{l}\text { Este subcriterio examina los procesos de la organización para es- } \\
\text { cuchar a la ciudadanía, determinar su satisfacción e insatisfacción, } \\
\text { analizar y utilizar los datos sobre su condición, a fin de mejorar su } \\
\text { imagen, construir una cultura más focalizada en ella e identificar } \\
\text { las oportunidades para la innovación. Además, enfatiza la manera } \\
\text { en que se obtiene información de la ciudadanía, para la toma de } \\
\text { decisiones. Dicha información debe estar vinculada con la oferta de } \\
\text { servicios y procesos clave de la organización, y debe ser usada para } \\
\text { determinar las implicaciones de costo/beneficio o efectividad, para } \\
\text { mejorar el establecimiento de metas y prioridades para el cambio } \\
\text { (MIDEPLAN, 2008). }\end{array}$ \\
\hline \multirow{2}{*}{$\begin{array}{l}\text { Medición, } \\
\text { análisis y } \\
\text { gestión del } \\
\text { conoci- } \\
\text { miento }\end{array}$} & \multirow{2}{*}{$\begin{array}{l}\text { El criterio medición, análisis y gestión del } \\
\text { conocimiento examina cómo la organiza- } \\
\text { ción selecciona, recolecta, analiza, gestio- } \\
\text { na y mejora sus datos, información y acti- } \\
\text { vos de conocimiento; y cómo gestiona su } \\
\text { tecnología de la información. Igualmente, } \\
\text { examina cómo la organización evalúa y } \\
\text { utiliza las evaluaciones para mejorar su } \\
\text { desempeño (MIDEPLAN, 2008). }\end{array}$} & $\begin{array}{l}\text { Medición, análisis y } \\
\text { mejora del desempeño } \\
\text { organizacional }\end{array}$ & $\begin{array}{l}\text { Este subcriterio analiza la selección, administración y uso de los } \\
\text { datos e información de la organización, para medir el desempeño y } \\
\text { analizarlo, con el propósito de respaldar la planificación y la mejora } \\
\text { del desempeño (MIDEPLAN, 2008). }\end{array}$ \\
\hline & & $\begin{array}{l}\text { Gestión de la información, } \\
\text { conocimiento y tecnología } \\
\text { de la información }\end{array}$ & $\begin{array}{l}\text { Este subcriterio analiza cómo la organización crea y maneja sus } \\
\text { recursos de conocimiento. El objetivo es mejorar la efectividad, la } \\
\text { eficienciay y la innovación de la organización (MIDEPLAN, 2008). }\end{array}$ \\
\hline \multirow{2}{*}{$\begin{array}{l}\text { Orientación } \\
\text { hacia el } \\
\text { talento } \\
\text { humano }\end{array}$} & \multirow{2}{*}{$\begin{array}{l}\text { El criterio orientación hacia el talento } \\
\text { humano, examina cómo la organización } \\
\text { compromete, administra y desarrolla el } \\
\text { talento humano para utilizar su máximo } \\
\text { potencial, alineado con la totalidad de su } \\
\text { misión, estrategia y planes de acción. El } \\
\text { Criterio examina la habilidad para evaluar } \\
\text { la idoneidad del talento humano, para } \\
\text { construir un ámbito conducente a un } \\
\text { desempeño de excelencia (MIDEPLAN, } \\
\text { 2008). }\end{array}$} & $\begin{array}{l}\text { Compromiso del talento } \\
\text { humano }\end{array}$ & $\begin{array}{l}\text { El subcriterio examina cómo los sistemas de la organización } \\
\text { consiguen comprometer, desarrollar y evaluar el compromiso del } \\
\text { talento humano, con la intención de capacitar y alentar a todos sus } \\
\text { miembros a que contribuyan efectivamente y desarrollen lo mejor } \\
\text { de sus capacidades (MIDEPLAN, 2008). }\end{array}$ \\
\hline & & $\begin{array}{l}\text { Ámbito del talento } \\
\text { humano }\end{array}$ & $\begin{array}{l}\text { Este subcriterio examina el ámbito de su talento humano, sus } \\
\text { necesidades de capacitación y habilidad y cómo se cumple con } \\
\text { aquellas necesidades para ejecutar el trabajo de la organización } \\
\text { (MIDEPLAN, 2008). }\end{array}$ \\
\hline
\end{tabular}




\begin{tabular}{|c|c|c|c|}
\hline & \multirow[b]{2}{*}{$\begin{array}{l}\text { El criterio gestión por procesos examina } \\
\text { cómo la organización diseña su sistema } \\
\text { de trabajo; cómo diseña, gestiona y } \\
\text { mejora sus procesos clave, para llevar a } \\
\text { cabo un sistema de trabajo que permita } \\
\text { entregar valor a la ciudadanía y alcanzar } \\
\text { el éxito organizacional y sostenible. } \\
\text { También examina su preparación ante } \\
\text { emergencias (MIDEPLAN, 2008). }\end{array}$} & Sistema de trabajo & $\begin{array}{l}\text { Este subcriterio examina el sistema de trabajo de la organización, } \\
\text { las competencias esenciales y la decisión sobre los procesos de tra- } \\
\text { bajo, con la intención de crear valor para la ciudadanía, prepararse } \\
\text { para emergencias potenciales y alcanzar el éxito de la organización } \\
\text { y su desarrollo sostenible (MIDEPLAN, 2008). }\end{array}$ \\
\hline $\begin{array}{l}\text { Gestión por } \\
\text { procesos }\end{array}$ & & Procesos de trabajo & $\begin{array}{l}\text { Los procesos de trabajo clave incluyen aquellos procesos orga- } \\
\text { nizacionales que no son servicios y que son considerados por } \\
\text { la alta dirección, más importantes para el crecimiento y el éxito } \\
\text { de la organización. Generalmente están relacionados con los } \\
\text { objetivos estratégicos de la organización y los factores críticos de } \\
\text { éxito. Deben incluir procesos para la innovación, investigación y } \\
\text { desarrollo, adquisición de tecnología, gestión de la información y } \\
\text { el conocimiento, gestión de la cadena de suministros, asociación } \\
\text { con proveedores, outsourcing, fusiones y adquisiciones, expansión } \\
\text { global, gestión de proyectos, ventas y marketing, así como aquellos } \\
\text { procesos de apoyo que respaldan día a día la entrega de un servicio. } \\
\text { Por lo general no están diseñados de manera detallada, conjunta- } \\
\text { mente con los servicios (MIDEPLAN, 2008). }\end{array}$ \\
\hline \multirow{5}{*}{ Resultados } & \multirow{5}{*}{$\begin{array}{l}\text { El criterio resultados, examina el des- } \\
\text { empeño organizacional y las mejoras en } \\
\text { todas las áreas clave como: resultados } \\
\text { de servicios, de la orientación a la ciu- } \\
\text { dadanía, del desempeño financiero, de } \\
\text { la gestión del talento humano, del des- } \\
\text { empeño operacional y del liderazgo. Los } \\
\text { niveles de desempeño de la organización, } \\
\text { se examinan en relación con otras organi- } \\
\text { zaciones con ofertas de servicios similares } \\
\text { (MIDEPLAN, 2008). }\end{array}$} & Resultados de servicios & $\begin{array}{l}\text { Este subcriterio analiza los resultados del desempeño de los ser- } \\
\text { vicios clave de la organización, con el objetivo de brindar servicios } \\
\text { de calidad para alcanzar satisfacción y compromiso (MIDEPLAN, } \\
\text { 2008). }\end{array}$ \\
\hline & & $\begin{array}{l}\text { Resultados de orientación } \\
\text { hacia la ciudadanía }\end{array}$ & $\begin{array}{l}\text { Este subcriterio examina los resultados de desempeño que se } \\
\text { centran en la ciudadanía, con el fin de demostrar de qué manera la } \\
\text { organización ha logrado satisfacer las necesidades y expectativas } \\
\text { de la ciudadanía y cómo ha logrado desarrollar su lealtad hacia la } \\
\text { organización (MIDEPLAN, 2008). }\end{array}$ \\
\hline & & $\begin{array}{l}\text { Resultados financieros del } \\
\text { talento humano }\end{array}$ & $\begin{array}{l}\text { Este subcriterio examina los resultados financieros clave de la } \\
\text { organización, a fin de comprender la sostenibilidad financiera, los } \\
\text { desafíos y las oportunidades en el entorno (MIDEPLAN, 2008). }\end{array}$ \\
\hline & & $\begin{array}{l}\text { Resultados de la efectivi- } \\
\text { dad de los procesos }\end{array}$ & $\begin{array}{l}\text { Este subcriterio, examina los otros resultados clave de los desempe- } \\
\text { ños organizacionales no reportados en los subcriterios } 7.1 \text { (resul- } \\
\text { tados de servicios) y } 7.4 \text { (resultados del talento humano), a fin de } \\
\text { alcanzar la efectividad y la eficiencia en los procesos de trabajo y en } \\
\text { el sistema de trabajo (MIDEPLAN, 2008). }\end{array}$ \\
\hline & & Resultados de liderazgo & $\begin{array}{l}\text { Este subcriterio examina los resultados en las áreas de liderazgo, } \\
\text { gestión de la organización, cumplimiento del plan estratégico y de } \\
\text { responsabilidad social, con el propósito de mantener una organiza- } \\
\text { ción ética y fiscalmente responsable, que cumpla sus responsabili- } \\
\text { dades sociales y apoye sus comunidades clave (MIDEPLAN, 2008). }\end{array}$ \\
\hline
\end{tabular}

Fuente: MIDEPLAN (2012) y Vásquez (2014). 
En la figura 6, los principios básicos se traducen en criterios de evaluación, los cuales se relacio- nan entre sí, para formar el modelo de calidad de la gestión pública (Henderson, 2011, p. 236).

FIGURA 6

\section{MARCO GENERAL DEL MODELO DE EXCELENCIA EN LA GESTIÓN, MEG: UNA PERSPECTIVA DE SISTEMA}

\section{Perfin organizacional}

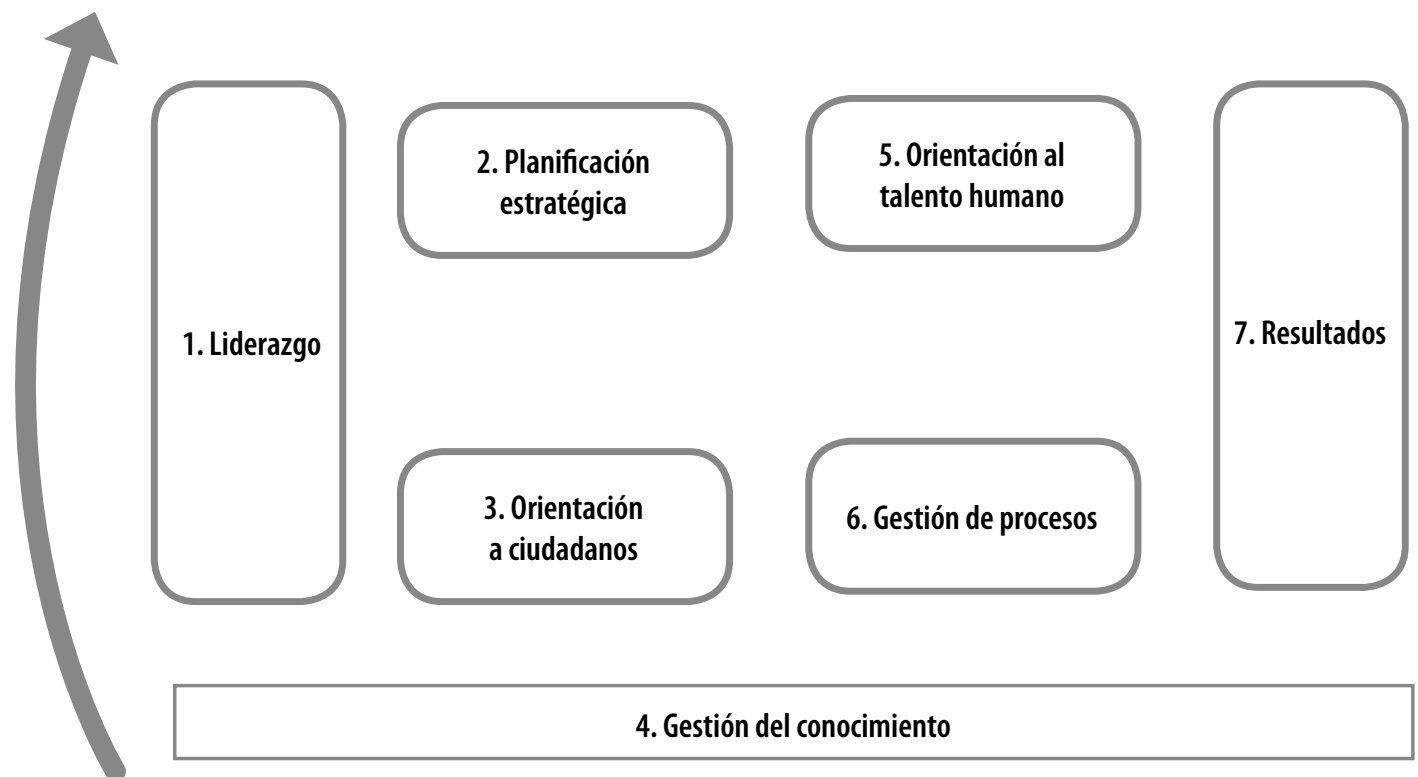

Fuente: Ministerio de Planificación Nacional y Política Económica, MIDEPLAN, y Dirección General del Servicio Civil, DGSC, Premio Nacional a la Calidad y Reconocimiento a Prácticas Promisorias en la Gestión Pública: bases del permio, 2010.

En el modelo el liderazgo, en conjunto con la planificación estratégica y la orientación al ciudadano, constituyen la tríada del liderazgo. La orientación hacia el talento humano, la gestión por procesos y los resultados, constituyen la tríada de los resultados. Transversal a ambas triadas encontramos la gestión del conoci- miento, fundamental para el liderazgo y para los resultados.

En la administración Chinchilla Miranda (2010-2014), se continuó con el impulso de Nueva Gestión Pública para América Latina del CLAD, en su componente calidad. Es así como en el Plan Nacional de Desarrollo 
"María Teresa Obregón Zamora", se contempló la imperiosa necesidad de "mejorar la eficiencia de los servicios públicos e incrementar el acceso de los ciudadanos a estos". (Vásquez, 2014, p. 47).

Para esto es necesario "fomentar una participación cada vez mayor de la ciudadanía en la solución de los problemas nacionales, mediante la construcción de agendas de desarrollo basadas en el diálogo y la integración" (MIDEPLAN, 2010, pág.41), y "mejorar la gestión pública, la calidad de los servicios que presta el Estado y la participación ciudadana en el accionar público" (MIDEPLAN, 2010, p. 219).

Desde su fundación el MIDEPLAN y la Dirección General de Servicio Civil, han sido los responsables del Premio Nacional.

Congruente con el Plan Nacional de DesarroIlo de la administración Chinchilla Miranda, en los años 2010, 2011 y 2012 se realizaron los primeros tres procesos para otorgar el Premio Nacional a la Calidad en la Gestión Pública y el reconocimiento a prácticas promisorias en la gestión pública.

En el año 2010, la Superintendencia de Pensiones (SUPEN) fue galardonada con el Premio Nacional a la Calidad, y el Banco Central de Costa Rica obtuvo la mención bronce; en el año 2011, el premio nacional fue otorgado al Instituto Costarricense de Electricidad (ICE), la mención categoría oro fue otorgada a la Empresa de Servicios Públicos de Heredia (ESPH) y la mención categoría plata, fue compartida por el Instituto Nacional de Aprendizaje (INA) y el Banco Central de Costa Rica (BCCR). En el 2012, el premio fue declarado desierto en todas las categorías.

\section{Conclusiones}

Los modelos de calidad de la gestión pública: EFQM, CAF, EVAM, FUNDIBEQ y la carta Iberoamericana de la Calidad, contienen una base y una columna común, que consiste en que la calidad es evaluada holísticamente, tomando en cuenta una serie de factores, y no únicamente el servicio per se, lo que era usual en la gestión privada de la primera mitad del Siglo $X X$, visión reduccionista que se filtra en el discurso político, incluso en la Costa Rica del Siglo $\mathrm{XXI}$.

Si bien el servicio público, que es el resultado de una organización pública, es importante en los modelos, a tal punto que en los modelos EFQM, CAF, EVAN y FUNDIBEQ constituye cerca de la mitad de la valoración de la calidad en la gestión pública, también son importantes otras dimensiones que permiten juzgar la calidad, como son: la evaluación del liderazgo, los procesos, el personal, la planificación estratégica y los colaboradores (alianzas) y recursos, que constituyen la otra parte importante.

Los resultados en los modelos EFQM, CAF, EVAN y FUNDIBEQ, son evaluados a partir de la segregación de cuatro factores, como son los resultados claves, los resultados en la sociedad, los resultados en los beneficiarios de la gestión y los resultados del desarrollo del personal de la organización.

Por su parte la Carta Iberoamericana en la Gestión Pública, apela a construir una cultura de la calidad, bajo principios de servicio público, legitimidad, participación ciudadana, legalidad, acceso universal, transparencia, ética pública, imparcialidad, responsabilidad, eficacia, eficiencia, economía y evaluación permanente y mejora continua. 
Los cinco modelos, tienen un eje común al identificar el sujeto último de la calidad, al darle éste papel al ciudadano, muchas veces denominado ciudadano-cliente, que es "más" que el simple cliente, visualizado éste como consumidor, de la gestión privada, en tanto es una persona con derechos y deberes, propios del ejercicio de la ciudadanía, eje fundamental de la democracia.

El modelo de calidad que fundamenta el Premio Nacional de la Calidad en la Gestión Pública en Costa Rica, retoma el enfoque holístico de la calidad de los modelos mencionados, por ella la gestión pública es evaluada a partir de la conjugación de varios factores, en donde es importante los resultados de la gestión, pero lo es también el liderazgo, la planificación estratégica, la orientación al talento humano y los procesos, dando privilegio a la gestión del conocimiento, en el entendido que se pretende evaluar la capacidad de aprender de la organización.

Desde la oficialización del premio, son pocas las organizaciones públicas que se han sometido a evaluación de la calidad en su gestión; incluso en su tercera edición el premio fue declarado desierto, lo cual es un indicador de la poca disponibilidad de las autoridades públicas, para que su gestión sea sometida a los parámetros de calidad nacional.

Si no hay un sometimiento de las autoridades a la evaluación nacional de la calidad de la gestión pública, sería entonces impensable, el sometimiento de la gestión nacional pública a la evaluación internacional, bajo los modelos: EFQM, CAF, EVAN y FUNDIBEQ, en tanto la primera evaluación es generalmente requisito para la segunda.

El estar renunciando a estas evaluaciones, significa que se está renunciando a identificar, bajo parámetros nacionales e internacionales, las oportunidades de mejora, requisito primor- dial para establecer la estrategia y la programación para la mejora de la calidad de la gestión pública costarricense. Lo que nos lleva a una pregunta final de cierre: ¿Estaremos los costarricenses imposibilitados de tener servicios públicos de calidad?

\section{Referencias}

Agencia Estatal de Evaluación de las Políticas Públicas y la Calidad de los Servicios. (AEVAL)(2009). Guía de evaluación. Modelo EVAM. Modelo de evaluación, aprendizaje y mejora. Madrid: Agencia Estatal de Evaluación de las Políticas Públicas y la Calidad de los Servicios.

Aguilera, G. (2010). Modelos de evaluación de la calidad de las organizaciones dependientes de la Administración Pública en México y en España. Tesis de doctorado, Universidad de Granada, Granada, España.

Altaba, E. (2010). La nueva gestión pública y la gestión por competencias. Tesis doctoral presentada en al Universitat Rovira I Virgilli, España.

Araya, E. y Cerpa, A. (2008). La nueva gestión pública y las reformas en la Administración Pública Chilena. Revista de Estudios Polítecnicos, VII (11). Recuperado de: http://www.scielo.oces.mctes.pt/pdf/tek/n11/ n11a03.pdf

Calderón, S. y Castellón L. (2011). Impulso a la Calidad en la gestión pública costarricense. Costa Rica: MIDEPLAN.

CLAD (2008). Carta lberoamericana de Calidad en la Gestión Pública. XVIII Cumbre Iberoamericana, El Salvador, octubre. Recuperado de: http://www.clad.org/documentos/declaraciones/carta-iberoamericana-decalidad-en-la-gestion-publica/view

Evans, J. y Lindsay M. (2008). Administración y Control de Calidad. México: Cengage Leaming Latin America,

Henderson, A. (2011). Los premios de la calidad en la gestión pública. Revista Centroamericana de Administración Pública, 60-61, 219-242.

Ministerio de Administraciones Públicas (MAP) ( 2006). El Modelo EVAM. España. 
RNA Revista Nacional de Administración

Ministerio de Planificación Nacional (MIDEPLAN) (2008). Guía del Premio Nacional a la Calidad en la Gestión Pública y Reconocimiento de Practicas Promisorias en la Gestión Pública. San José: MIDEPLAN

Muñoz, M. (1999). La gestión de calidad total en la administración pública. España:Ediciones Díaz de Santos.

Vásquez, J. (2014). La Institucionalidad de la Calidad de los Servicios Públicos en Costa Rica. Revista Nacional de Administración, 5(1), 31-48.

Recibido: 27 de mayo de 2014 Aceptado: 12 de agosto de 2014 